\title{
Production of high-purity phospholipid concentrate from buttermilk powder using ethanol-modified supercritical carbon dioxide
}

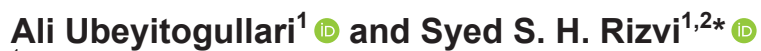 \\ ${ }^{1}$ Department of Food Science, Cornell University, Ithaca, NY 14850 \\ ${ }^{2}$ School of Chemical and Biomolecular Engineering, Cornell University, Ithaca, NY 14850
}

\begin{abstract}
A new strategy to concentrate phospholipids from buttermilk powder was developed using a food-grade green method based on ethanol-modified supercritical carbon dioxide $\left(\mathrm{SC}-\mathrm{CO}_{2}\right)$ extraction. The effects of extraction conditions, namely temperature (50 and $60^{\circ} \mathrm{C}$ ), pressure (30 and $\left.40 \mathrm{MPa}\right)$, and ethanol concentration $(10,15$, and $20 \%$, wt/wt), on the total lipid yield and phospholipid content were investigated. The ethanol concentration had a more significant effect on the total lipid yield and phospholipid content than the temperature and pressure within the ranges studied. The highest phospholipid recovery was achieved at $60^{\circ} \mathrm{C}, 30 \mathrm{MPa}$, and $15 \%$ (wt/wt) ethanol with a total lipid yield of $6.3 \%$ (wt/wt), of which $49 \%$ (wt/wt) were phospholipids composed of dihydrosphingomyelin (5\%), sphingomyelin (24\%), phosphatidylethanolamine (22\%), phosphatidylserine (2\%), phosphatidylinositol (3\%), and phosphatidylcholine (44\%). The triacylglycerol compositions of extracts obtained by Folch and ethanol-modified $\mathrm{SC}-\mathrm{CO}_{2}$ extractions were similar. A sequential pure $\mathrm{SC}-\mathrm{CO}_{2}$ and ethanol-modified $\mathrm{SC}-\mathrm{CO}_{2}$ extraction was carried out to separate nonpolar lipids in the first fraction, thereby concentrating phospholipids in the second fraction. This sequential extraction produced a highly concentrated phospholipid extract $(76 \%$, wt/wt). To the best of our knowledge, this is the highest phospholipid concentration reported from buttermilk powder. Thus, this phospholipid-rich extract can be used in the development of functional foods as a food-grade emulsifier with potential health-promoting effects.
\end{abstract}

Key words: buttermilk, phospholipid, supercritical carbon dioxide, ethanol, extraction

\footnotetext{
Received April 11, 2020.

Accepted May 30, 2020.

*Corresponding author: srizvi@cornell.edu
}

\section{INTRODUCTION}

In recent years, the food industry has prioritized the use of functional-food ingredients to design healthpromoting food products. Traditionally, phospholipids, mostly sourced from soybean, have been incorporated into foods as emulsifiers due to their amphiphilic nature (containing both a hydrophilic head and a hydrophobic tail; Sun et al., 2018). Among phospholipids, milk fat globule membrane (MFGM) phospholipids have received much attention, owing to their composition, stability, and potential health benefits (Singh, 2006; Thompson et al., 2009; Contarini and Povolo, 2013). In particular, MFGM phospholipids are reported to have antiproliferative activity against human ovary and colon cancer cells (Castro-Gómez et al., 2016), stimulate the development and outgrowth of cortical neurons (Barry et al., 2018), and inhibit infection caused by rotavirus in vitro (Fuller et al., 2013). In addition, sphingomyelin (SM) present in the MFGM has been associated with several health benefits such as improving cell growth and regulation (Contarini and Povolo, 2013), suppressing Alzheimer's disease (Gallier et al., 2010), and protecting against hypercholesterolemia (Noh and Koo, 2004) and cancer (Duan and Nilsson, 2009). Moreover, MFGM phospholipids provide exceptional functional properties such as improved heat stability in emulsions (Kasinos et al., 2014), increased oxidation resistance in liposome membranes (Thompson and Singh, 2006), and higher loading capacities in liposomes (Thompson et al., 2009). The MFGM phospholipid concentrates (Phospholac 600 and PC 700 with $~ 70$ and $60 \%$ phospholipid contents, respectively) developed by Fonterra Co-operative Group Ltd. (Auckland, New Zealand) have the highest phospholipid content reported thus far. Yet, the source and processing steps of those concentrates are not known due to trade secret practices (Thompson and Singh, 2006; Thompson et al., 2009; Price et al., 2018). However, the number of high-purity MFGM phospholipid concentrates are still scarce. Therefore, there is a critical need for a food-grade approach to isolate and purify MFGM phospholipids, ideally, from inexpensive dairy sources. 
Buttermilk is the liquid fraction obtained after churning cream during the butter-making process. It is rich in MFGM phospholipids $(\sim 15$ times higher phospholipid content than whole milk), abundant, and relatively inexpensive (Barry et al., 2017). Therefore, buttermilk is a great candidate for producing MFGM phospholipid concentrates. Specifically, spray-dried buttermilk powder contains a relatively high phospholipid content, mainly composed of phosphatidylethanolamine (PE; 8-17\%), phosphatidylcholine (PC; 46-51\%), SM (22$28 \%$ ), phosphatidylinositol (PI; 7-8\%), and phosphatidylserine (PS; 5-8\%; Contarini and Povolo, 2013). In addition, the high presence of SM and PS contents in MFGM differentiates buttermilk powder from other major lecithin sources, including soybean and egg yolk (Price et al., 2018).

Considering the need of MFGM phospholipids and their health benefits, significant efforts have been made to concentrate them from buttermilk powder (Huang et al., 2020). Thus far, 2 main approaches have been implemented. The first approach is based on the extraction of both polar and nonpolar lipids from buttermilk powder using solvents such as chloroform, hexane, ethanol, methanol, petroleum ether and N,N-dimethylcyclohexylamine (Gallier et al., 2010; Castro-Gómez et al., 2016; Cheng et al., 2019). The other approach aims to increase the relative concentration of MFGM phospholipids by removing sugars, proteins, and nonpolar lipids from buttermilk powder (Astaire et al., 2003; Spence et al., 2009b; Costa et al., 2010). For example, membrane filtration coupled with supercritical carbon dioxide $\left(\mathbf{S C}-\mathbf{C O}_{2}\right)$ extraction has been investigated to increase the concentration of phospholipids in buttermilk powder. Briefly, buttermilk was microfiltered or ultrafiltered, spray dried, and then subjected to $\mathrm{SC}-\mathrm{CO}_{2}$ extraction to remove the nonpolar lipids (Astaire et al., 2003; Costa et al., 2010). However, the use of toxic organic solvents and low phospholipid concentrations in the products (less than $10 \%$ using the microfiltration-coupled $\mathrm{SC}-\mathrm{CO}_{2}$ method; Spence et al., 2009b) drastically limits their food applications.

Supercritical $\mathrm{CO}_{2}$ has been considered a green solvent for the extraction of lipids from various sources because $\mathrm{CO}_{2}$ is nontoxic, inexpensive, abundant, environmentally friendly, and has a moderate critical temperature $\left(31^{\circ} \mathrm{C}\right)$ and pressure $(7.4 \mathrm{MPa})$. Although $\mathrm{SC}-\mathrm{CO}_{2}$ is a great solvent to extract nonpolar lipids, it has limited solvating power for polar lipids because of its nonpolar nature. Nevertheless, the solvating power of $\mathrm{SC}-\mathrm{CO}_{2}$ can be altered by introducing solvent modifiers. Ethanol, a food-grade solvent, can be incorporated into SC$\mathrm{CO}_{2}$ as a cosolvent to increase its polarity and, in turn, enhance the extraction of polar lipids such as MFGM phospholipids (Savoire et al., 2020). Previously, etha- nol-modified $\mathrm{SC}-\mathrm{CO}_{2}$ was used to extract phospholipids from various sources such as whey protein phospholipid concentrate (WPPC; Sprick et al., 2019), camelina press cake and scallop byproducts (Savoire et al., 2020), soybeans (Montanari et al., 1999), salmon byproducts (Haq and Chun, 2018), and chia seeds (Calvo et al., 2020b). As stated above, $\mathrm{SC}-\mathrm{CO}_{2}$ has been primarily used to extract the nonpolar lipids while retaining the phospholipids in buttermilk powder (Astaire et al., 2003; Spence et al., 2009a,c; Costa et al., 2010). To the best of our knowledge, there are only 2 reports on the use of $\mathrm{SC}-\mathrm{CO}_{2}$ with ethanol as a cosolvent to extract polar lipids from buttermilk powder (Barry et al., 2017; Li, 2017). In the study of Barry et al. (2017), phospholipids (56\% purity) were extracted from spray-dried $50-\mathrm{kDa}$ retentate that was produced by enzymatic hydrolysis and $50-\mathrm{kDa}$ membrane ultrafiltration of buttermilk. Nonetheless, the ethanol-modified $\mathrm{SC}-\mathrm{CO}_{2}$ extraction was investigated only at constant operating conditions $\left(40^{\circ} \mathrm{C}\right.$ and $\left.30 \mathrm{MPa}\right)$ with a very long extraction time of 13 h (Barry et al., 2017). Similarly, Li (2017) investigated the extraction of phospholipids from buttermilk powder using ethanol-modified SC- $\mathrm{CO}_{2}\left(60^{\circ} \mathrm{C}\right.$ and 55 $\mathrm{MPa}$ ), which again yielded a low phospholipid purity (17\%). Consequently, there is a need for a detailed investigation of extraction conditions to improve the isolation of phospholipids from buttermilk powder using a single-step process.

The main objective of this study was to generate a MFGM phospholipid-rich food ingredient from buttermilk powder. Specific objectives were to (1) investigate the effects of the ethanol-modified $\mathrm{SC}-\mathrm{CO}_{2}$ extraction conditions (temperature, pressure, and ethanol concentration) on the lipid yield and composition, (2) characterize the extracts for their phospholipid and triacylglycerol content and composition, and (3) fractionate the buttermilk powder lipids using a sequential pure $\mathrm{SC}-\mathrm{CO}_{2}$ followed by ethanol-modified SC- $\mathrm{CO}_{2}$ extraction.

\section{MATERIALS AND METHODS}

\section{Materials}

Dry buttermilk powder was obtained from Land O'Lakes, Inc. (Arden Hills, MN). Liquid $\mathrm{CO}_{2}$ (99.99\% purity) was supplied by Airgas, Inc. (Ithaca, NY). Ethanol (100\%) was acquired from Decon Labs, Inc. (King of Prussia, PA). Triacylglycerol standards were purchased from Nu-Chek Prep Inc. (Elysian, MN). Deuterium oxide was acquired from Cambridge Isotope Laboratories, Inc. (Andover, MA). Sodium cholate was obtained from Chem-Impex Int'l Inc. (Wood Dale, IL). All other chemicals were of analytical grade. 


\section{Folch Lipid Extraction}

Total lipid extraction from buttermilk powder was carried out following the method of Folch et al. (1957). First, buttermilk powder was mixed with methanol to dissociate lipid-protein interactions (Gallier et al., 2010). Then, chloroform was added to extract lipids. The ratio of chloroform to methanol was 2:1 ( $\mathrm{vol} / \mathrm{vol}$ ), and the buttermilk powder:solvent ratio was 1:20 (wt/ vol). The extraction was repeated 3 times and the extracts were pooled. Subsequently, the lipid extract was filtered through Whatman \#42 filter paper and concentrated using a rotary evaporator (Rotavapor-R, Büchi Labortechnik AG, Flawil, Switzerland) under vacuum at $35^{\circ} \mathrm{C}$. Finally, the residual solvent was removed by blowing nitrogen at room temperature $\left(21^{\circ} \mathrm{C}\right)$. The total lipid content was determined by weighing this solvent-free extract. The samples were stored at $-20^{\circ} \mathrm{C}$ under a blanket of nitrogen until further analysis. The total lipid yield was calculated as follows:

Total lipid yield $(\%)=\frac{\text { wt of solvent free extract }}{\text { wt of buttermilk powder }} \times 100$.

\section{$\mathrm{SC}-\mathrm{CO}_{2}$ Extraction}

$\mathrm{SC}-\mathrm{CO}_{2}$ extractions were performed using a laboratory-scale $\mathrm{SC}-\mathrm{CO}_{2}$ extraction system (SFT-250, Supercritical Fluid Technologies Inc., Newark, DE). The schematic diagram of the system is depicted in Figure 1. Briefly, $30 \mathrm{~g}$ of buttermilk powder were mixed with $30 \mathrm{~g}$ of nonporous glass beads to enhance mass transfer properties. Then, the mixture was loaded into a high-pressure vessel $(100 \mathrm{~mL})$, and a glass wool was placed at both ends of the vessel. The system was flushed with $\mathrm{CO}_{2}$ to eliminate any air in the vessel at ambient conditions. After flushing with $\mathrm{CO}_{2}$, the vessel was heated to the set temperature $\left(50\right.$ or $\left.60^{\circ} \mathrm{C}\right)$ and the micrometering valve was heated to $70^{\circ} \mathrm{C}$ to prevent freezing due to the Joule Thompson effect. Afterward, the system was pressurized with $\mathrm{CO}_{2}(30$ or $40 \mathrm{MPa})$ using a high-pressure $\mathrm{CO}_{2}$ pump (5 in Figure 1). The temperature and pressure of the system were controlled by PID-fuzzy logic controllers. For the ethanol-modified SC- $\mathrm{CO}_{2}$ extractions, the cosolvent pump (miniPump, Milton Roy Company, Ivyland, PA) was turned on to deliver ethanol to the system at a concentration of 10 , 15 , or $20 \%$ (wt/wt). The flow rates of ethanol were predetermined to obtain the required ethanol concentrations in the extraction vessel. After 20 min of static extraction time, the flow rate of $\mathrm{CO}_{2}$ was adjusted to $1 \mathrm{~L} / \mathrm{min}$ (measured at ambient conditions) using the micrometering valve. The extraction was continued for $4 \mathrm{~h}$, and the extracted lipids were collected in a sample vial kept in an ice bath. Ethanol was then removed from the samples in a vacuum oven at $40^{\circ} \mathrm{C}$. The complete removal of ethanol was ensured by consecutive weight measurements of the vials. Finally, the samples were flushed with nitrogen and stored at $-20^{\circ} \mathrm{C}$ until characterized. The total lipid yield was calculated using Equation [1].

\section{Fractionation of the Buttermilk Lipids Using $\mathrm{SC}-\mathrm{CO}_{2}$}

Fractionation of buttermilk lipids into nonpolar and polar lipids was carried out using the same $\mathrm{SC}-\mathrm{CO}_{2}$ extraction system described above. The nonpolar lipid fraction (first fraction) was extracted first using neat $\mathrm{SC}-\mathrm{CO}_{2}$ at the optimized extraction conditions. The extraction of the nonpolar lipids was conducted for 3 $\mathrm{h}$ at a $\mathrm{CO}_{2}$ flow rate of $1 \mathrm{~L} / \mathrm{min}$ (measured at ambient conditions). Then, ethanol was introduced to separate the polar lipids (second fraction) following the ethanolmodified SC- $\mathrm{CO}_{2}$ extraction procedure described above. The optimized ethanol-modified $\mathrm{SC}-\mathrm{CO}_{2}$ extraction conditions were used for the extraction of polar lipids. The nonpolar and polar lipid yields were calculated using the equation below:

$$
\text { Lipid yield }(\%)=\frac{\text { wt of the extract }}{\text { wt of buttermilk powder }} \times 100,[2]
$$

where the nonpolar and polar lipid yields were determined using weights of the extracts obtained by neat $\mathrm{SC}-\mathrm{CO}_{2}$ extraction or ethanol-modified SC- $\mathrm{CO}_{2}$ extraction, respectively.

\section{Phospholipid Analysis}

Phospholipids in the extracts were identified and quantified using a nuclear magnetic resonance (NMR) spectrometer (Bruker Avance III HD 500, Billerica, MA) according to the method of MacKenzie et al. (2009). A detergent solution of sodium cholate $(10 \%, \mathrm{wt} / \mathrm{wt})$ and EDTA (1\%, wt/wt) was prepared in an aqueous solution of deuterium oxide $(20 \%, \mathrm{vol} / \mathrm{vol})$. Then, the $\mathrm{pH}$ of the detergent solution was adjusted to 7.1 using a 1 $M \mathrm{NaOH}$ solution. The samples (30 mg) were mixed with $750 \mu \mathrm{L}$ of the detergent solution, and $50 \mu \mathrm{L}$ of $\mathrm{K}_{2} \mathrm{HPO}_{4}(6 \mathrm{mg} / \mathrm{mL})$ was added as an internal standard. The samples were placed in an ultrasonic water bath (T-500-3, Terriss-Consolidated Industries, Asbury Park, NJ) at $60^{\circ} \mathrm{C}$ for 10 min with occasional vortexing. The proton-decoupled ${ }^{31} \mathrm{P}$ NMR spectra were collected at $202.3 \mathrm{MHz}$ with 128 scans, 2.0 s recycle delay, and 


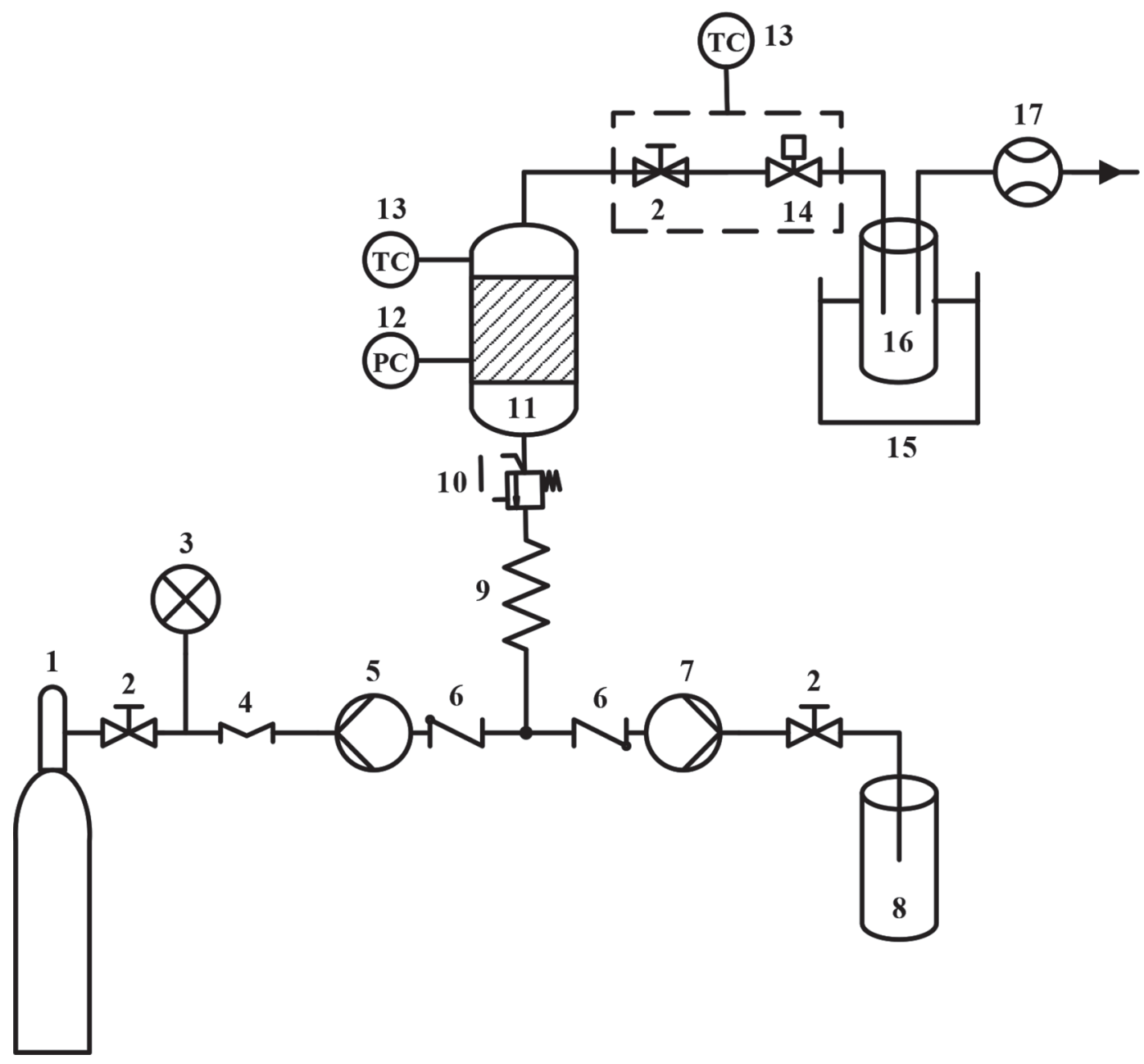

Figure 1. Schematic diagram of the supercritical carbon dioxide extraction system. Tags: $1=\mathrm{CO}_{2}$ cylinder; $2=$ needle valve; $3=$ pressure gauge; $4=$ pre-chiller; $5=$ high-pressure pump for $\mathrm{CO}_{2} ; 6=$ check valve; $7=$ high-pressure pump for cosolvent; $8=\operatorname{cosolvent;~} 9=$ preheater; $10=$ rupture disc; $11=$ high-pressure vessel; $12=$ pressure controller $(\mathrm{PC}) ; 13=$ temperature controller $(\mathrm{TC}) ; 14=$ micrometering valve; $15=$ cold trap; $16=$ sample vial; $17=$ flow meter.

$81.5 \mathrm{kHz}$ spectral width. The spectra were recorded and analyzed by TopSpin 3.5 (Bruker, Billerica, MA) and MestRenova 14.1 (Mestrelab Research S.L., Santiago de Compostela, Spain), respectively. The quantification of phospholipids was carried out by relating the area of each analyte to the area and molar concentration of the internal standard.

\section{Triacylglycerol Composition}

The triacylglycerol composition of the extracts was determined using GC (HP 5890 Series II, Agilent Technologies, Wilmington, DE) equipped with a flame ionization detector according to the method of Wagner et al. (2013). Before the triacylglycerol analysis, phospholipids were separated from the extracts by acid degumming (Xie and Dunford, 2019). Briefly, $1 \mathrm{~g}$ of extract was mixed with $30 \mu \mathrm{L}$ of citric acid solution $(10 \%$, wt $/$ wt) at $80^{\circ} \mathrm{C}$ for $1 \mathrm{~h}$. Then, the mixture was centrifuged at $11,340 \times g$ for 5 min (IMC-15, International Biotechnologies Inc., New Haven, CT), and $10 \mathrm{mg}$ of the supernatant was dissolved in chloroform $(5 \mathrm{~mL})$. After dilution, an aliquot $(1 \mu \mathrm{L})$ of the sample was injected onto a GC column (MET-Biodiesel, $14 \mathrm{~m} \times 0.53 \mathrm{~mm}$ $\times 0.16 \mu \mathrm{m}$; Supelco Inc., Bellefonte, PA) with a retention gap $(2 \mathrm{~m} \times 0.53 \mathrm{~mm})$. The oven temperature was programmed with an initial hold at $200^{\circ} \mathrm{C}$ for $1 \mathrm{~min}$, followed by an increase to $350^{\circ} \mathrm{C}$ at a rate of $25^{\circ} \mathrm{C} / \mathrm{min}$ and kept at $350^{\circ} \mathrm{C}$ for 5 min. Helium was used as the carrier gas with a constant column-head pressure of 62 $\mathrm{kPa}$. The injector and detector temperatures were set to 300 and $380^{\circ} \mathrm{C}$, respectively. Triacylglycerols were identified based on carbon number by comparing the retention times of the authentic triacylglycerol stan- 
dards, and their composition was calculated using the relative response factors and reported as percentages of the total triacylglycerols.

\section{Statistical Analysis}

The results are presented as the mean values \pm standard deviations. Statistical analyses of the data were carried out using Minitab 16.1.1 software (Minitab Inc., State College, PA). We used ANOVA and Tukey's multiple comparison test to determine the statistical differences among the treatments at a significance level of $P<0.05$. All experiments were conducted in triplicate. All composition values are reported in weight percentages, unless otherwise stated.

\section{RESULTS AND DISCUSSION}

\section{Effects of Extraction Conditions on the Total Lipid Yield}

Figure 2 depicts the effects of $\mathrm{SC}-\mathrm{CO}_{2}$ conditions, namely temperature and pressure, at varying ethanol concentrations on the total lipid yield. The extraction conditions were selected based on the literature and preliminary experiments (Spence et al., 2009a; Costa et al., 2010). The extraction time was set to $4 \mathrm{~h}$ according to the preliminary extraction curve data. The highest total lipid yield $(7.5 \pm 0.5 \%)$ was achieved with ethanol-modified $\mathrm{SC}-\mathrm{CO}_{2}$ extraction at $60^{\circ} \mathrm{C}, 30 \mathrm{MPa}$, and $20 \%$ ethanol. At higher ethanol concentrations, the total lipid yield increased as the temperature increased from 50 to $60^{\circ} \mathrm{C}$. For example, the total-lipid yield significantly increased from approximately 5 to $7 \%$ with the temperature increase at an ethanol concentration of $20 \%$ (Figure 2; $P<0.05$ ). On the other hand, changes in extraction pressure did not significantly affect the total lipid yield across the pressure range studied (30 and $40 \mathrm{MPa}$ ). In a previous study, Sprick et al. (2019) also did not observe any significant change in lipid yield from WPPC when pressure was increased from 35 to $55 \mathrm{MPa}$. Similar results were reported by Li (2017), as well. Although higher pressures enhance solvating power of $\mathrm{SC}-\mathrm{CO}_{2}$ due to the increase in density, changing the pressure from 30 to $40 \mathrm{MPa}$ at $60^{\circ} \mathrm{C}$ slightly increased the density of $\mathrm{SC}-\mathrm{CO}_{2}$, from 830 to $890 \mathrm{~kg} /$ $\mathrm{m}^{3}$, respectively (Lemmon et al., 2020), which therefore had a limited effect on the total lipid yield (Figure 2). Furthermore, the presence of ethanol can enable the same extraction efficiency at lower pressures (Cocero and Calvo, 1996). Similarly, changing the extraction temperature and pressure at low ethanol concentration $(10 \%)$ did not significantly alter the total lipid yield $(P$ $>0.05)$.
Studying the effects of temperature and pressure separately on the lipid yield is very challenging because both temperature and pressure of $\mathrm{SC}-\mathrm{CO}_{2}$ dictate its mass transfer properties and consequently, its solvating power. In general, the solvating power of $\mathrm{SC}_{-} \mathrm{CO}_{2}$ increases with the increase in its density. Thus, increasing pressure at constant temperature improves the extractability of pure $\mathrm{SC}-\mathrm{CO}_{2}$. The influence of temperature is not as straightforward, however. An increase in temperature decreases the density of $\mathrm{SC}-\mathrm{CO}_{2}$, inhibiting extraction, but increases the vapor pressure of the solutes, enhancing extraction. This phenomenon is known as the crossover of solubility isotherms when the pressure determines which effect is dominant (decrease in the density or increase in the solute vapor pressure; Güçlü-Üstündağ and Temelli, 2004). The crossover pressure for milk fat triacylglycerols is expected to be between 20 and $25 \mathrm{MPa}$ because the solubility of milk fat triacylglycerols in $\mathrm{SC}-\mathrm{CO}_{2}$ decreased with a temperature increase from 50 to $80^{\circ} \mathrm{C}$ at approximately 20 MPa (Arul et al., 1994). Yet, their solubility increased with temperature at pressures above $25 \mathrm{MPa}$ (Arul et al., 1994). Therefore, the total lipid yield increased with increasing temperature at isobaric conditions, as both pressures investigated (30 and $40 \mathrm{MPa}$ ) were above the crossover pressure (Figure 2). Ethanol concentration also played a critical role in determining the total lipid yield, as discussed below. The findings of this study agreed with the theoretical lipid solubility parameters reported by Spence et al. (2009a), where the solubility of the lipids increased with temperature. However, whereas Spence et al. (2009a) obtained higher lipid solubility from buttermilk powder with a temperature increase from 40 to $50^{\circ} \mathrm{C}$, they observed a decrease in lipid solubility at $60^{\circ} \mathrm{C}$. Interestingly, the fat reduction from buttermilk powder did not significantly change with temperature $\left(40,50\right.$, and $\left.60^{\circ} \mathrm{C}\right)$ at any pressure $(15,25$, and $35 \mathrm{MPa})$ in their study (Spence et al., 2009a).

Ethanol was introduced to the extraction system to increase the polarity of the solvent mixture and efficiently extract both polar and nonpolar lipids. In preliminary studies, an ethanol concentration of $5 \%$ was investigated, but the total lipid yield was relatively low $(\sim 2 \%)$. Therefore, $5 \%$ ethanol concentration was excluded from further study and the effects of 10, 15, and $20 \%$ ethanol were investigated in detail. Although increasing ethanol concentration from 10 to $15 \%$ mostly increased the total lipid yield (Figure 2), further increasing the ethanol concentration did not significantly increase the total lipid yield $(P>0.05)$. For instance, the total lipid yields obtained at $60^{\circ} \mathrm{C}$ and $30 \mathrm{MPa}$ with ethanol concentrations of 10,15 , and $20 \%$ were $2.8,6.3$, and $7.5 \%$, respectively. The increases in the total lipid 


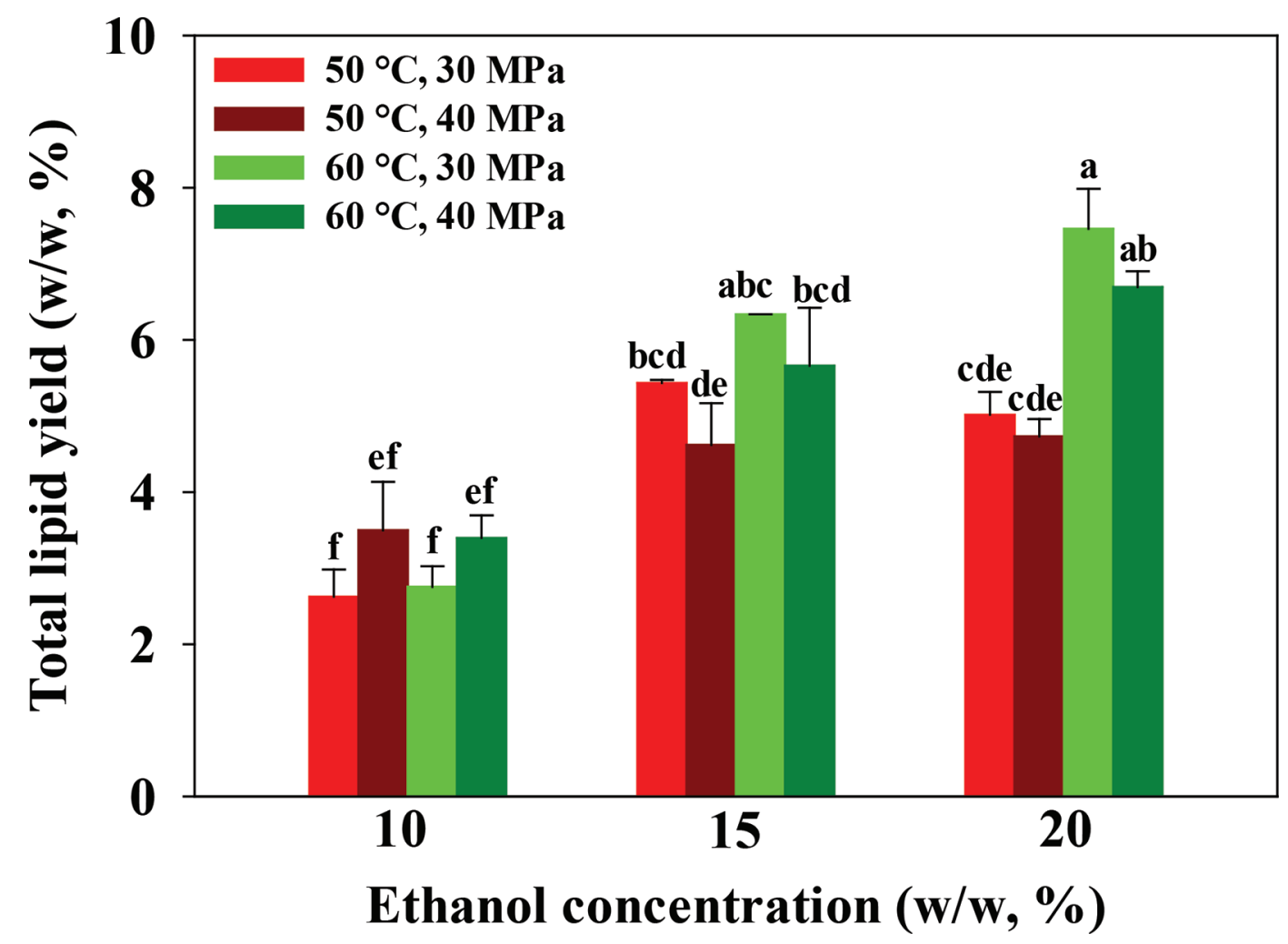

Figure 2. Effect of ethanol concentration on the total lipid yield at varying extraction temperatures and pressures. Means with different letters $(\mathrm{a}-\mathrm{f})$ are significantly different $(P<0.05)$. Error bars show SD of 3 replicates.

yield can largely be explained by the increased recovery of polar lipids from the buttermilk powder. Furthermore, as ethanol extracted the polar lipids from the MFGM, the nonpolar lipids in the core became more accessible to the $\mathrm{SC}-\mathrm{CO}_{2}$ (Lopez et al., 2014), further increasing the total lipid yield. In addition, nonpolar lipids may have acted as a cosolvent and increased the extraction of polar lipids (Cocero and Calvo, 1996). Recently, Savoire et al. (2020) observed similar effects of ethanol concentration on the total lipid yield from camelina press cakes and scallop byproducts, when the total lipid yield increased with increasing ethanol concentration from 7 to $15 \%$, but did not change with a further increase to $30 \%$ at $45^{\circ} \mathrm{C}$ and $25 \mathrm{MPa}$ (Savoire et al., 2020).

\section{Effects of Extraction Conditions on the Phospholipid Content}

The phospholipids in the extracts obtained by ethanol-modified $\mathrm{SC}-\mathrm{CO}_{2}$ extraction were identified and quantified using ${ }^{31} \mathrm{P}$ NMR (Figure 3). The major phospholipids present in the extracts were DHSM, SM, PE, PS, PI, and PC with ${ }^{31} \mathrm{P}$ NMR signals at $\delta-0.09$ $\mathrm{ppm}, \delta-0.18 \mathrm{ppm}, \delta-0.23 \mathrm{ppm}, \delta-0.44 \mathrm{ppm}, \delta-0.66$ ppm, and $\delta-0.79 \mathrm{ppm}$, respectively. Similar ${ }^{31} \mathrm{P}$ NMR chemical shifts of dairy phospholipids have previously been reported (MacKenzie et al., 2009). Minor phospholipids, namely, 2-lysophosphatidylethanolamine and 2-lysophosphatidylcholine were also observed in some samples at $\delta-0.20 \mathrm{ppm}$ and $\delta-0.34 \mathrm{ppm}$, respectively. However, their concentration was very low as indicated by their low peak intensities (Figure 3 ). In addition, the signal at $\delta 1.40 \mathrm{ppm}$, corresponding to $\mathrm{K}_{2} \mathrm{HPO}_{4}$, did not interfere with other peaks and was used as an internal standard to quantify phospholipids.

The total phospholipid contents (sum of all phospholipids) of the ethanol-modified $\mathrm{SC}-\mathrm{CO}_{2}$ extracts are presented in Figure 4. The highest total phospholipid content (49\%) was attained with the extraction at $60^{\circ} \mathrm{C}, 30 \mathrm{MPa}$, and $15 \%$ ethanol concentration. This phospholipid content was not significantly altered when the extraction pressure or ethanol concentration were increased at the same temperature $\left(60^{\circ} \mathrm{C}\right)$. At higher ethanol concentrations ( 15 and $20 \%$ ), increasing the temperature significantly improved the extraction of phospholipids at both pressures studied $(P<0.05)$, which was due to the increase in the solubility of phospholipids and enhanced mass transfer properties (Baümler et al., 2017; Sprick et al., 2019). Alterna- 


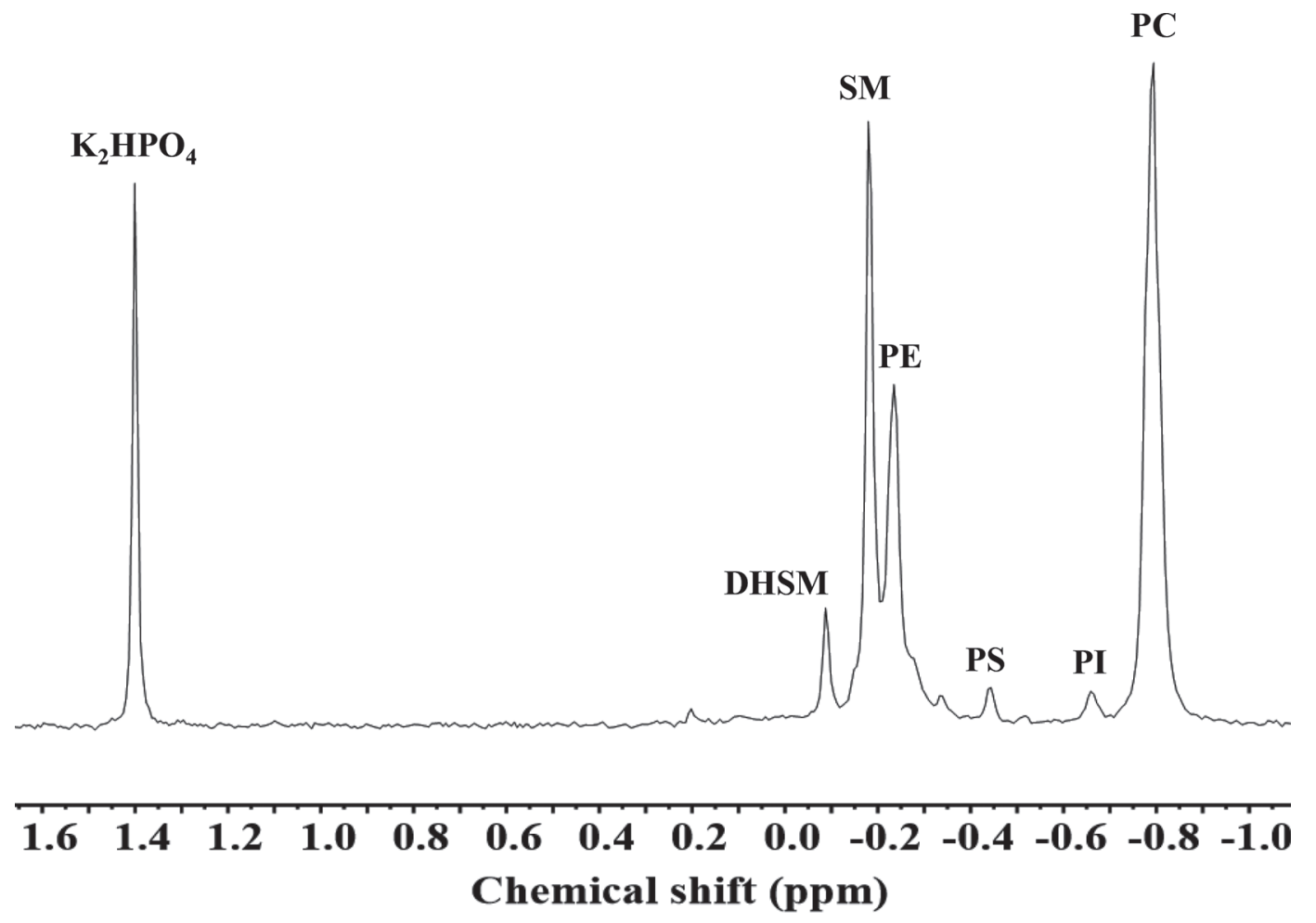

Figure 3. ${ }^{31} \mathrm{P}$ nuclear magnetic resonance spectrum of the polar lipids in the buttermilk powder extract. DHSM = dihydrosphingomyelin; SM $=$ sphingomyelin $; \mathrm{PE}=$ phosphatidylethanolamine; $\mathrm{PS}=$ phosphatidylserine; $\mathrm{PI}=$ phosphatidylinositol; $\mathrm{PC}=$ phosphatidylcholine.

tively, increasing the pressure from 30 to $40 \mathrm{MPa}$ did not affect the total phospholipid content in most of the extraction conditions (Figure 4), which agreed with the total-lipid yield data (Figure 3).

Ethanol concentration had a larger influence on the total phospholipid yield than temperature or pressure (Figure 4). As expected, the total phospholipid yield drastically increased - from approximately 6 to $40 \%$ - when the ethanol concentration increased from 10 to $15 \%$, due to the increase in the solvent polarity (Catchpole et al., 2009). Nevertheless, further increases in ethanol concentrations did not improve the phospholipid extraction. Previously, Sprick et al. (2019) studied the extraction of lipids from WPPC using $\mathrm{SC}-\mathrm{CO}_{2}$ and ethanol as a cosolvent, where the effects of temperature $\left(40-60^{\circ} \mathrm{C}\right)$, pressure $(35-55 \mathrm{MPa})$, and ethanol concentration (10-20\%) on phospholipid recovery were investigated. They similarly found that increasing ethanol concentration from 10 to $15 \%$ enhanced the phospholipid extraction, but that further increase did not improve phospholipid recovery (Sprick et al., 2019). In another study, the extraction of phospholipids from buttermilk $50-\mathrm{kDa}$ retentate was carried out using ethanol concentrations of 10 and $20 \%$ at a constant extraction temperature $\left(40^{\circ} \mathrm{C}\right)$ and pressure $(30 \mathrm{MPa}$; Barry et al., 2017). Similarly, they found that an etha- nol concentration of $10 \%$ was not able to extract any phospholipids from the buttermilk 50-kDa retentate, whereas an ethanol concentration of $20 \%$ significantly improved phospholipid extraction (Barry et al., 2017).

\section{Comparison of Folch and Ethanol-Modified $\mathrm{SC}-\mathrm{CO}_{2}$ Extractions}

Folch extraction was performed to determine the total lipid content of the buttermilk powder because it has the capability of extracting both polar and nonpolar lipids (Gallier et al., 2010; Price et al., 2018). The total lipid content of buttermilk powder was $9.0 \pm$ $0.2 \%$, which was composed of $59.8 \pm 0.5 \%$ phospholipids. Correspondingly, the buttermilk powder contained a considerable amount of phospholipids (5.4\%). The major components of buttermilk powder were previously reported as 31 to $38 \%$ protein, 5 to $17 \%$ lipids, approximately $52 \%$ lactose, and approximately $7 \%$ ash (Astaire et al., 2003; Spence et al., 2009c; Barry et al., 2017), with variation mostly due to the source and processing of the buttermilk powder. The total lipid content $(9 \%)$ of the buttermilk powder used for extractions fell within the range of lipid contents previously reported. Gallier et al. (2010) measured a similar total lipid content (10\%) by the Folch extraction using but- 


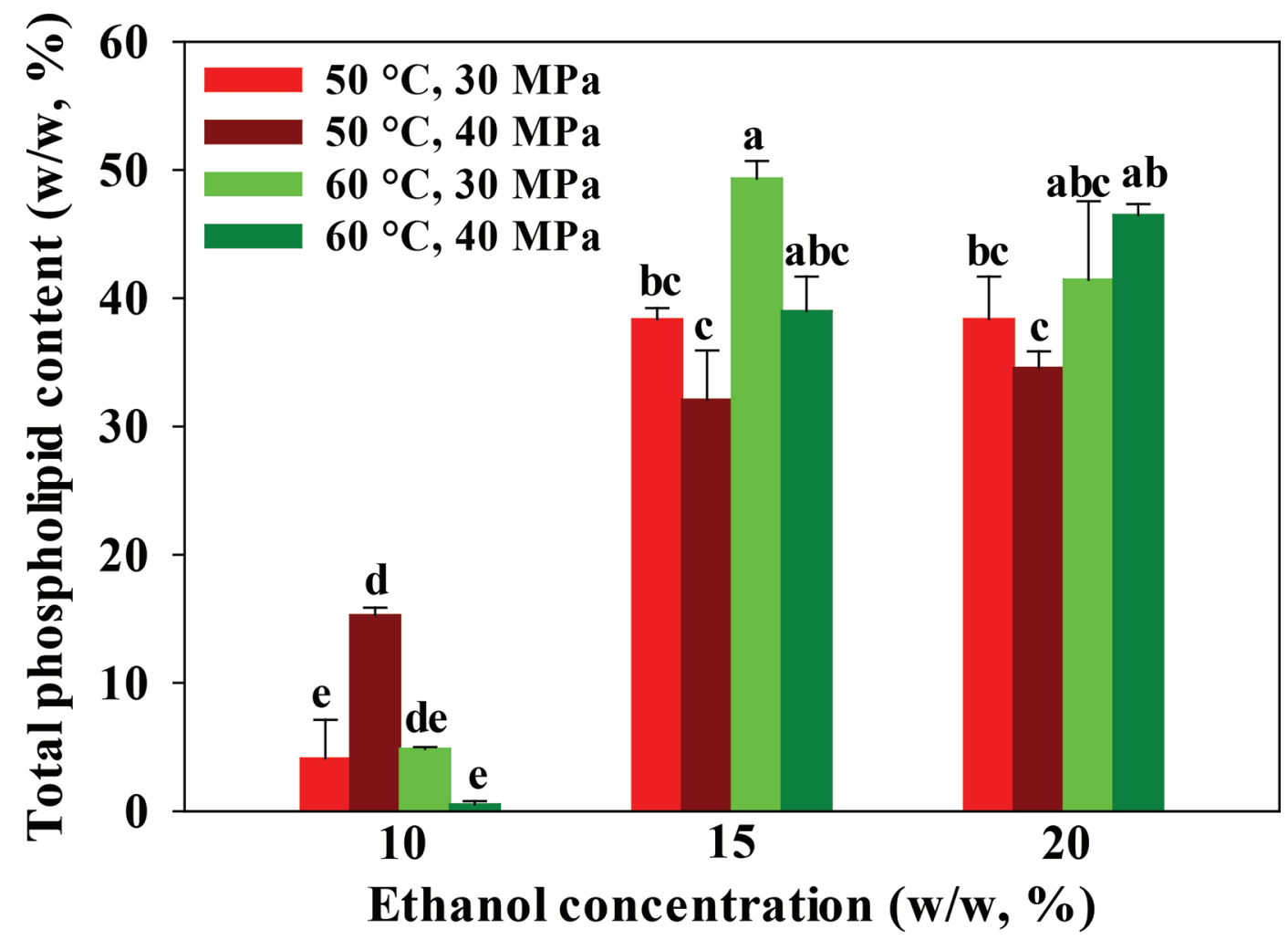

Figure 4. Effects of ethanol concentration, temperature, and pressure on the total phospholipid contents of the extracts. Means with different letters $(\mathrm{a}-\mathrm{e})$ are significantly different $(P<0.05)$. Error bars show SD of 3 replicates.

termilk powder from the same supplier. Nonetheless, the total phospholipid content of the buttermilk powder used in this study was higher than the previously reported values: $3.3 \%$ by Phan et al. (2013) and $1.3 \%$ by Barry et al. (2017). This discrepancy could simply be due to the use of a different buttermilk powder source, as previously stated. However, the phospholipid content of buttermilk powder measured in this study (5.4\%) still fell within literature values for other buttermilk products: $11.1 \%$ in buttermilk $50-\mathrm{kDa}$ retentate (Barry et al., 2017) and 7.2\% in whey buttermilk powder (Costa et al., 2010).

Optimal ethanol-modified $\mathrm{SC}-\mathrm{CO}_{2}$ conditions were determined based on the total lipid yield and phospholipid content of the extract to maximize phospholipid recovery from the buttermilk powder. Because the phospholipid recovery for extractions carried out at $60^{\circ} \mathrm{C}$ did not significantly improve with further increases in pressure (30 vs. $40 \mathrm{MPa}$ ) and ethanol concentration (15 vs. $20 \%$ ), the optimum extraction conditions were chosen as $60^{\circ} \mathrm{C}, 30 \mathrm{MPa}$, and $15 \%$ ethanol to minimize energy consumption and optimize process economics. The extraction at these optimized conditions yielded a phospholipid recovery of $58 \%$.
The phospholipid compositions of the extracts obtained by Folch and ethanol-modified SC- $\mathrm{CO}_{2}$ extractions are presented in Table 1 . The predominant phospholipids in buttermilk powder were DHSM (3.8\%), SM $(33.2 \%), \mathrm{PE}(25.1 \%)$, PS $(5.1 \%)$, PI $(3.9 \%)$, and PC $(28.9 \%)$, as determined by ${ }^{31} \mathrm{P}$ NMR analysis of the Folch-extracted lipid fraction. In the literature, the content of major phospholipids in buttermilk powder varied between 0 and $4.6 \%$ DHSM, 20.4 and $43.1 \%$ SM, 18.6 and $25.7 \%$ PE, 6.3 and $9.7 \%$ PS, 0.7 and $10.8 \%$ PI, and 27.0 and $31.3 \%$ PC (MacKenzie et al., 2009; Spence et al., 2009b; Barry et al., 2017). Variation in these values was due to the buttermilk source as well as the extraction and analysis techniques (Gallier et al., 2010). On the other hand, the phospholipids in the ethanol-modified $\mathrm{SC}-\mathrm{CO}_{2}$ extract obtained at the optimized extraction conditions were composed of $5.0 \%$ DHSM, $24.3 \%$ SM, $22.1 \%$ PE, $2.2 \%$ PS, $2.7 \%$ PI, and $43.6 \%$ PC, which were significantly different from the phospholipid composition attained by Folch extraction $(P<0.05)$. Among phospholipids, $\mathrm{PC}$ was more favorably extracted by ethanol-modified $\mathrm{SC}-\mathrm{CO}_{2}$, owing to its higher solubility in the ethanol-SC- $\mathrm{CO}_{2}$ mixture (Catchpole et al., 2009). Therefore, the ratio of PC was 


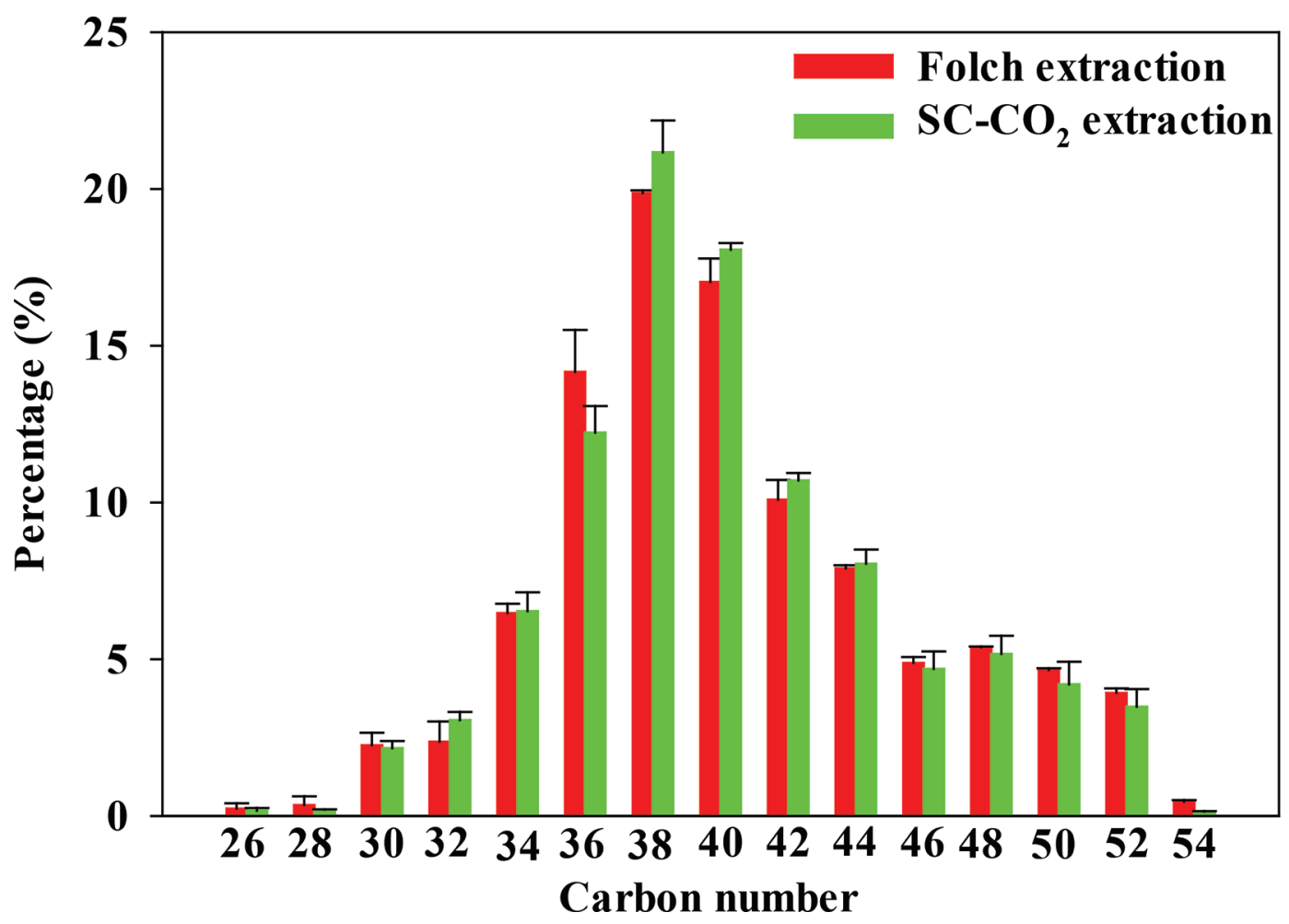

Figure 5. Triacylglycerol composition of the nonpolar lipids obtained by Folch and ethanol-modified supercritical carbon dioxide $\left.\left(\mathrm{SC}^{-\mathrm{CO}}\right)_{2}\right)$ extractions. Error bars show SD of 3 replicates.

increased from 28.9 to $43.6 \%$ when ethanol-modified SC- $\mathrm{CO}_{2}$ extraction was implemented instead of Folch extraction.

Furthermore, the triacylglycerol compositions of the Folch and ethanol-modified SC- $\mathrm{CO}_{2}$ extracts are shown in Figure 5. The ethanol-modified $\mathrm{SC}-\mathrm{CO}_{2}$ extract obtained at the optimized extraction conditions $\left(60^{\circ} \mathrm{C}\right.$, $30 \mathrm{MPa}$, and $15 \%$ ethanol) was used for triacylglycerol composition analysis. Phospholipids were separated before the GC-FID analysis to eliminate the co-elution of polar lipids with low molecular weight triacylglycerols (Castro-Gómez et al., 2017). Both extraction methods resulted in similar triacylglycerol distributions where CN34, CN36, CN38, CN40, CN42, and CN44 (where $\mathrm{CN}=$ carbon number) were the major triacylglycerols with ratios of approximately $7,13,20,18,9$, and $8 \%$, respectively. Similar triacylglycerol compositions were reported by Castro-Gómez et al. (2017) and Calvo et al. (2020a).

\section{Fractionation of Buttermilk Lipids}

Fractionation of the buttermilk lipids was carried out using a sequential pure $\mathrm{SC}-\mathrm{CO}_{2}$ and ethanol-modified $\mathrm{SC}-\mathrm{CO}_{2}$ extraction. Table 2 shows the total lipid yields and their phospholipid contents obtained by Folch extraction from the original buttermilk powder, and pure $\mathrm{SC}-\mathrm{CO}_{2}$ (the first fraction) and ethanol-modified $\mathrm{SC}-\mathrm{CO}_{2}$ (the second fraction) extraction. The buttermilk powder contained $9.0 \%$ total lipids, which was

Table 1. Phospholipid composition $(\%)^{1}$ of the extracts obtained by Folch and ethanol-modified supercritical carbon dioxide $\left(\mathrm{SC}^{-\mathrm{CO}}{ }_{2} ; 60^{\circ} \mathrm{C}\right.$ and $30 \mathrm{MPa})$ extractions from buttermilk powder

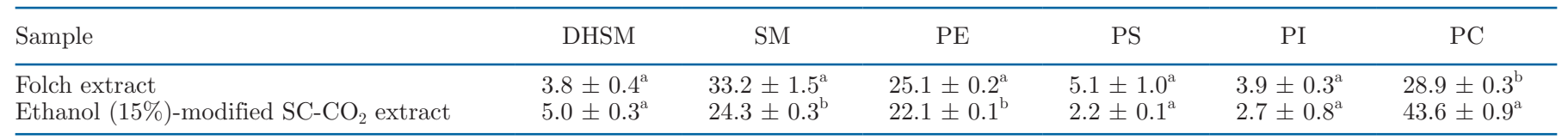

\footnotetext{
${ }_{\mathrm{a}, \mathrm{b}}$ Means in the same column with different superscripts are significantly different $(P<0.05)$.

${ }^{1}$ Data are expressed as means $\pm \mathrm{SD}$. DHSM = dihydrosphingomyelin; $\mathrm{SM}=$ sphingomyelin; $\mathrm{PE}=$ phosphatidylethanolamine; PS $=$ phosphatidylserine; PI = phosphatidylinositol; PC = phosphatidylcholine.
} 
Table 2. Material balance ${ }^{1}$ of the Folch and sequential supercritical carbon dioxide $\left(\mathrm{SC}^{\left.-\mathrm{CO}_{2}\right)}\right.$ extractions from $100 \mathrm{~g}$ of buttermilk powder

\begin{tabular}{|c|c|c|c|}
\hline \multirow[b]{2}{*}{ Item } & \multirow{2}{*}{$\begin{array}{c}\text { Folch } \\
\begin{array}{c}\text { Chloroform:methanol } \\
(2: 1, \mathrm{vol} / \mathrm{vol})\end{array}\end{array}$} & \multicolumn{2}{|c|}{ Sequential SC- $\mathrm{CO}_{2}$ fractions } \\
\hline & & $\begin{array}{l}\text { I. Pure SC-CO } \mathrm{CO}_{2} \\
\left(60^{\circ} \mathrm{C}, 40 \mathrm{MPa}\right)\end{array}$ & $\begin{array}{l}\text { II. } 15 \% \text { ethanol-modified } \mathrm{SC}-\mathrm{CO}_{2} \\
\left(60^{\circ} \mathrm{C}, 30 \mathrm{MPa}\right)\end{array}$ \\
\hline Phospholipids (wt/wt, \% of total lipids) & $59.8 \pm 0.5^{\mathrm{b}}$ & $0.2 \pm 0.1^{\mathrm{c}}$ & $76.2 \pm 2.0^{\mathrm{a}}$ \\
\hline
\end{tabular}

${ }^{\mathrm{a}-\mathrm{c}}$ Means in the same row with different superscripts are significantly different $(P<0.05)$.

${ }^{1}$ Data are expressed as means $\pm \mathrm{SD}$.

composed of $60 \%$ polar lipids. Therefore, the sequential pure $\mathrm{SC}-\mathrm{CO}_{2}$ and ethanol-modified $\mathrm{SC}-\mathrm{CO}_{2}$ extraction was able to recover $75 \%$ of the total lipids present in the buttermilk powder.

The first part of the sequential extraction was performed using pure $\mathrm{SC}-\mathrm{CO}_{2}$ at $60^{\circ} \mathrm{C}$ and $40 \mathrm{MPa}$, when the highest total lipid yield was achieved (Figure 2). The total lipid yield of the pure $\mathrm{SC}-\mathrm{CO}_{2}$ extraction (first fraction) was $2.5 \pm 0.2 \%$. This fraction was rich in triacylglycerols and contained only $0.25 \pm 0.03 \%$ phospholipids. On the other hand, the second part of the extraction, resulting in the second fraction, was carried out at the optimized ethanol-modified $\mathrm{SC}-\mathrm{CO}_{2}$ extraction conditions $\left(60^{\circ} \mathrm{C}\right.$ and $30 \mathrm{MPa}$ with $15 \%$ ethanol). The second fraction had a significantly higher total lipid yield $(4.3 \pm 0.2 \%)$ compared with the first fraction $(2.5 \%, P<0.05)$ due to an increased extraction of polar lipids (Table 2). The total phospholipid content was also maximized in the second fraction (76.2 \pm $2.0 \%$ ). Whereas the phospholipid content significantly increased from 49 to $76 \%$ with the pure $\mathrm{SC}-\mathrm{CO}_{2}$ preextraction, the phospholipid composition of the second fraction (5.8\% DHSM, 26.6\% SM, 18.3\% PE, 1.8\% PS, $4.1 \% \mathrm{PI}$, and $43.4 \% \mathrm{PC}$ ) was similar to that obtained without pure $\mathrm{SC}_{-} \mathrm{CO}_{2}$ pre-extraction (Table 1). Similarly, the triacylglycerol composition of the nonpolar lipids did not change with the fractionation extractions.

Thus far, the highest phospholipid content from a fraction of buttermilk powder (spray-dried 50-kDa retentate), $56.2 \%$, was obtained by Barry et al. (2017), following a similar approach using pure $\mathrm{SC}-\mathrm{CO}_{2}$ and ethanol-modified $\mathrm{SC}-\mathrm{CO}_{2}$ extraction $\left(40^{\circ} \mathrm{C}, 30 \mathrm{MPa}\right.$, and $20 \%$ ethanol). However, the buttermilk used for $\mathrm{SC}-\mathrm{CO}_{2}$ extraction was pretreated with enzymatic hydrolysis, ultrafiltration, and spray drying, adding cost and complexity. Also, the total extraction time was $13 \mathrm{~h}$ (Barry et al., 2017). In this study, a significantly higher phospholipid purity (76\%) was attained in a shorter extraction time $(7 \mathrm{~h})$. Likewise, Li (2017) extracted phospholipids from buttermilk powder using a 2-stage pure $\mathrm{SC}-\mathrm{CO}_{2}$ and ethanol-modified SC- $\mathrm{CO}_{2}$ extraction $\left(60^{\circ} \mathrm{C}, 55 \mathrm{MPa}\right.$, and $15 \%$ ethanol), producing an extract with a relatively low phospholipid content (17\%). In that study, the first stage of the extraction was carried out at $41.4 \mathrm{MPa}$ and $60^{\circ} \mathrm{C}$ for a short period of time (1 h) using pure $\mathrm{SC}-\mathrm{CO}_{2}$. These conditions may have resulted in an inefficient extraction of nonpolar lipids due to limited contact time, leaving most of the nonpolar lipids available for the second stage of the extraction, and consequently producing an extract with low phospholipid content (Li, 2017). In another approach to purify phospholipids, Spence et al. (2009b) concentrated phospholipids in the buttermilk powder by removing the nonpolar lipids using $\mathrm{SC}-\mathrm{CO}_{2}$ extraction, enriching the phospholipid content of the buttermilk powder to $9 \%$. Nevertheless, the $\mathrm{SC}-\mathrm{CO}_{2}$ treated buttermilk powder was still mostly composed of proteins $(\sim 50 \%$; Spence et al., 2009b). Moreover, the phospholipid content of the whey buttermilk powder, pretreated by ultrafiltration, increased from 7.2 to $12.0 \%$ using SC$\mathrm{CO}_{2}$ extraction (Costa et al., 2010). Yet, the presence of other macromolecules in those products drastically limits their applications.

\section{CONCLUSIONS}

In this study, phospholipid-rich lipid extracts were isolated from buttermilk powder using a green approach based on $\mathrm{SC}-\mathrm{CO}_{2}$ technology. Extraction conditions were investigated and optimized for the highest phospholipid recovery from buttermilk powder. Ethanol concentration had a larger influence on the lipid yield and phospholipid content than extraction temperature or pressure. The optimized ethanol-modified $\mathrm{SC}-\mathrm{CO}_{2}$ extraction conditions were $60^{\circ} \mathrm{C}, 30 \mathrm{MPa}$, and $15 \%$ ethanol, which resulted in a $6.3 \%$ total lipid yield. The resulting extract contained a high phospholipid content (49\%); the major phospholipids were DHSM (5.0\%), SM $(24.3 \%)$, PE $(22.1 \%)$, PS $(2.2 \%)$, PI $(2.7 \%)$, and PC $(43.6 \%)$. The PC was selectively extracted by ethanol-modified $\mathrm{SC}-\mathrm{CO}_{2}$, and was therefore enriched relative to its concentration in the buttermilk powder $(28.9 \%)$. The triacylglycerol compositions of the ethanol-modified $\mathrm{SC}-\mathrm{CO}_{2}$ and Folch extracts were similar. Furthermore, fractionation of nonpolar and polar buttermilk lipids was achieved by a sequential 
pure $\mathrm{SC}-\mathrm{CO}_{2}$ followed by ethanol-modified $\mathrm{SC}-\mathrm{CO}_{2}$ extraction. Selectively extracting nonpolar lipids in the first fraction with pure $\mathrm{SC}-\mathrm{CO}_{2}$ resulted in a second fraction concentrated in phospholipids (76\%). The method developed in this study produced a high-purity phospholipid concentrate using only food-grade materials, namely ethanol and $\mathrm{SC}-\mathrm{CO}_{2}$. This environmentally friendly process has a promising potential for a largescale production. Thus, the phospholipid-rich extract can be used as a new source of emulsifier in numerous functional food preparations.

\section{ACKNOWLEDGMENTS}

This project was supported by Agriculture and Food Research Initiative (USDA-AFRI, Grant Number 201767017-26474, Washington, DC) from the United States Department of Agriculture National Institute of Food and Agriculture (USDA NIFA). This work made use of the NMR facility at Cornell University that is funded in part by the NSF under the Award Number CHE1531632. The authors also thank Andrew Melnychenko and Connor Smith (Department of Food Science, Cornell University, Ithaca, NY) for their help in this work. The authors have not stated any conflicts of interest.

\section{REFERENCES}

Arul, J., R. Tardif, A. Boudreau, D. S. McGinnis, and R. W. Lencki. 1994. Solubility of milk fat triglycerides in supercritical carbon dioxide. Food Res. Int. 27:459-467. https://doi.org/10.1016/0963 -9969(94)90240-2.

Astaire, J. C., R. Ward, J. B. German, and R. Jiménez-Flores. 2003. Concentration of polar MFGM lipids from buttermilk by microfiltration and supercritical fluid extraction. J. Dairy Sci. 86:22972307. https://doi.org/10.3168/jds.S0022-0302(03)73822-3.

Barry, K. M., T. G. Dinan, and P. M. Kelly. 2017. Pilot scale production of a phospholipid-enriched dairy ingredient by means of an optimised integrated process employing enzymatic hydrolysis, ultrafiltration and super-critical fluid extraction. Innov. Food Sci. Emerg. Technol. 41:301-306. https://doi.org/10.1016/j.ifset.2017 .04 .004 .

Barry, K. M., T. G. Dinan, C. Stanton, and P. M. Kelly. 2018. Investigation of the neurotrophic effect of dairy phospholipids on cortical neuron outgrowth and stimulation. J. Funct. Foods 40:60-67. https://doi.org/10.1016/j.jff.2017.10.005.

Baümler, E. R., M. E. Carrín, and A. A. Carelli. 2017. Diffusion of tocopherols, phospholipids and sugars during oil extraction from sunflower collets using ethanol as solvent. J. Food Eng. 194:1-8. https://doi.org/10.1016/j.jfoodeng.2016.09.003.

Calvo, M. V., M. C. Martín-Hernández, A. García-Serrano, M. P. Castro-Gómez, L. Alonso-Miravalles, R. García-Martín, J. MeginoTello, L. Alonso, and J. Fontecha. 2020a. Comprehensive characterization of neutral and polar lipids of buttermilk from different sources and its milk fat globule membrane isolates. J. Food Compos. Anal. 86:103386. https://doi.org/10.1016/j.jfca.2019.103386.

Calvo, M. V., D. Villanueva-Bermejo, P. Castro-Gómez, T. Fornari, and J. Fontecha. 2020b. Appraisal of the suitability of two-stage extraction process by combining compressed fluid technologies of polar lipid fractions from chia seed. Food Res. Int. 131:109007. https://doi.org/10.1016/j.foodres.2020.109007.
Castro-Gómez, P., O. Montero, and J. Fontecha. 2017. In-depth lipidomic analysis of molecular species of triacylglycerides, diacylglycerides, glycerophospholipids, and sphingolipids of buttermilk by GC-MS/FID, HPLC-ELSD, and UPLC-QToF-MS. Int. J. Mol. Sci. 18:605. https://doi.org/10.3390/ijms18030605.

Castro-Gómez, P., L. M. Rodríguez-Alcalá, K. M. Monteiro, A. L. T. G. Ruiz, J. E. Carvalho, and J. Fontecha. 2016. Antiproliferative activity of buttermilk lipid fractions isolated using food grade and non-food grade solvents on human cancer cell lines. Food Chem. 212:695-702. https://doi.org/10.1016/j.foodchem.2016.06.030.

Catchpole, O. J., S. J. Tallon, W. E. Eltringham, J. B. Grey, K. Fenton, E. M. Vagi, M. V. Vyssotski, N. MacKenzie, J. Ryan, and Y. Zhu. 2009. The extraction and fractionation of specialty lipids using near critical fluids. J. Supercrit. Fluids 47:591-597. https:// doi.org/10.1016/j.supflu.2008.10.008.

Cheng, S., K. Rathnakumar, and I. S. Martínez-Monteagudo. 2019. Extraction of dairy phospholipids using switchable solvents: A feasibility study. Foods 8:265. https://doi.org/10.3390/foods8070265.

Cocero, M. J., and L. Calvo. 1996. Supercritical fluid extraction of sunflower seed oil with $\mathrm{CO}_{2}$-ethanol mixtures. J. Am. Oil Chem. Soc. 73:1573-1578. https://doi.org/10.1007/BF02523527.

Contarini, G., and M. Povolo. 2013. Phospholipids in milk fat: Composition, biological and technological significance, and analytical strategies. Int. J. Mol. Sci. 14:2808-2831. https://doi.org/10.3390/ ijms14022808.

Costa, M. R., X. E. Elias-Argote, R. Jiménez-Flores, and M. L. Gigante. 2010. Use of ultrafiltration and supercritical fluid extraction to obtain a whey buttermilk powder enriched in milk fat globule membrane phospholipids. Int. Dairy J. 20:598-602. https://doi .org/10.1016/j.idairyj.2010.03.006.

Duan, R.-D., and $\AA$. Nilsson. 2009. Metabolism of sphingolipids in the gut and its relation to inflammation and cancer development. Prog. Lipid Res. 48:62-72. https://doi.org/10.1016/j.plipres.2008 .04 .003 .

Folch, J., M. Lees, and G. H. S. Stanley. 1957. A simple method for the isolation and purification of total lipids from animal tissues. J. Biol. Chem. 226:497-509.

Fuller, K. L., T. B. Kuhlenschmidt, M. S. Kuhlenschmidt, R. JiménezFlores, and S. M. Donovan. 2013. Milk fat globule membrane isolated from buttermilk or whey cream and their lipid components inhibit infectivity of rotavirus in vitro. J. Dairy Sci. 96:3488-3497. https://doi.org/10.3168/jds.2012-6122.

Gallier, S., D. Gragson, C. Cabral, R. Jiménez-Flores, and D. W. Everett. 2010. Composition and fatty acid distribution of bovine milk phospholipids from processed milk products. J. Agric. Food Chem. 58:10503-10511. https://doi.org/10.1021/jf101878d.

Güçlü-Üstündağ. Ö., and F. Temelli. 2004. Correlating the solubility behavior of minor lipid components in supercritical carbon dioxide. J. Supercrit. Fluids 31:235-253. https://doi.org/10.1016/j .supflu.2003.12.007.

Haq, M., and B.-S. Chun. 2018. Characterization of phospholipids extracted from Atlantic salmon by-product using supercritical $\mathrm{CO}_{2}$ with ethanol as co-solvent. J. Clean. Prod. 178:186-195. https:// doi.org/10.1016/j.jclepro.2018.01.024.

Huang, Z., H. Zheng, S. C. Brennan, S. M. Mohan, L. Stipkovits, L. Li, and D. Kulasiri. 2020. Production of milk phospholipidenriched dairy ingredients. Foods 9:263. https://doi.org/10.3390/ foods9030263.

Kasinos, M., T. Tran Le, and P. Van der Meeren. 2014. Improved heat stability of recombined evaporated milk emulsions upon addition of phospholipid enriched dairy by-products. Food Hydrocoll. 34:112-118. https://doi.org/10.1016/j.foodhyd.2012.11.030.

Lemmon, E. W., M. O. McLinden, and D. G. Friend. 2020. Thermophysical properties of fluid systems. in NIST Chemistry WebBook, NIST Standard Reference Database Number 69. P. J. Linstrom and W. G. Mallard, ed. National Institute of Standards and Technology, Gaithersburg, MD.

Li, B. 2017. Selective extraction of phospholipids from dairy powders using supercritical fluid extraction. MS thesis. Department of Food Science, Kansas State University, Manhattan, KS. 
Lopez, C., V. Briard-Bion, and O. Ménard. 2014. Polar lipids, sphingomyelin and long-chain unsaturated fatty acids from the milk fat globule membrane are increased in milks produced by cows fed fresh pasture based diet during spring. Food Res. Int. 58:59-68. https://doi.org/10.1016/j.foodres.2014.01.049.

MacKenzie, A., M. Vyssotski, and E. Nekrasov. 2009. Quantitative analysis of dairy phospholipids by 31P NMR. J. Am. Oil Chem. Soc. 86:757-763. https://doi.org/10.1007/s11746-009-1403-6.

Montanari, L., P. Fantozzi, J. M. Snyder, and J. W. King. 1999. Selective extraction of phospholipids from soybeans with supercritical carbon dioxide and ethanol. J. Supercrit. Fluids 14:87-93. https:/ /doi.org/10.1016/S0896-8446(98)00110-7.

Noh, S. K., and S. I. Koo. 2004. Milk sphingomyelin is more effective than egg sphingomyelin in inhibiting intestinal absorption of cholesterol and fat in rats. J. Nutr. 134:2611-2616. https://doi.org/10 $.1093 / \mathrm{jn} / 134.10 .2611$

Phan, T. T. Q., M. Asaduzzaman, T. T. Le, E. Fredrick, P. Van der Meeren, and K. Dewettinck. 2013. Composition and emulsifying properties of a milk fat globule membrane enriched material. Int. Dairy J. 29:99-106. https://doi.org/10.1016/j.idairyj.2012.10.014.

Price, N., T. Fei, S. Clark, and T. Wang. 2018. Extraction of phospholipids from a dairy by-product (whey protein phospholipid concentrate) using ethanol. J. Dairy Sci. 101:8778-8787. https://doi.org/ $10.3168 / j d s .2018-14950$.

Savoire, R., P. Subra-Paternault, T. Bardeau, E. Morvan, A. Grélard, and M. Cansell. 2020. Selective extraction of phospholipids from food by-products by supercritical carbon dioxide and ethanol and formulating ability of extracts. Separ. Purif. Tech. 238:116394. https://doi.org/10.1016/j.seppur.2019.116394.

Singh, H. 2006. The milk fat globule membrane-A biophysical system for food applications. Curr. Opin. Colloid Interface Sci. 11:154163. https://doi.org/10.1016/j.cocis.2005.11.002.

Spence, A. J., R. Jimenez-Flores, M. Qian, and L. Goddik. 2009a. The influence of temperature and pressure factors in supercritical fluid extraction for optimizing nonpolar lipid extraction from buttermilk powder. J. Dairy Sci. 92:458-468. https://doi.org/10.3168/ jds.2008-1278.

Spence, A. J., R. Jimenez-Flores, M. Qian, and L. Goddik. 2009b. Phospholipid enrichment in sweet and whey cream buttermilk powders using supercritical fluid extraction. J. Dairy Sci. 92:23732381. https://doi.org/10.3168/jds.2008-1534.

Spence, A. J., R. Jimenez-Flores, M. Qian, and L. Goddik. 2009c. Short communication: Evaluation of supercritical fluid extraction aids for optimum extraction of nonpolar lipids from buttermilk powder. J. Dairy Sci. 92:5933-5936. https://doi.org/10.3168/jds .2009-2286.

Sprick, B., Z. Linghu, J. K. Amamcharla, L. E. Metzger, and J. S. Smith. 2019. Selective extraction of phospholipids from whey protein phospholipid concentrate using supercritical carbon dioxide and ethanol as a co-solvent. J. Dairy Sci. 102:10855-10866. https: //doi.org/10.3168/jds.2019-16419.

Sun, N., J. Chen, D. Wang, and S. Lin. 2018. Advance in food-derived phospholipids: Sources, molecular species and structure as well as their biological activities. Trends Food Sci. Technol. 80:199-211. https://doi.org/10.1016/j.tifs.2018.08.010.

Thompson, A. K., A. Couchoud, and H. Singh. 2009. Comparison of hydrophobic and hydrophilic encapsulation using liposomes prepared from milk fat globule-derived phospholipids and soya phospholipids. Dairy Sci. Technol. 89:99-113. https://doi.org/10.1051/ dst/2008036.

Thompson, A. K., and H. Singh. 2006. Preparation of liposomes from milk fat globule membrane phospholipids using a microfluidizer. J. Dairy Sci. 89:410-419. https://doi.org/10.3168/jds.S0022 -0302(06)72105-1.

Wagner, M. E., J. French, and S. S. H. Rizvi. 2013. Supercritical fluid extraction of oil from potato chips: Two scale comparison and mathematical modeling. J. Food Eng. 118:100-107. https://doi .org/10.1016/j.jfoodeng.2013.03.023.

Xie, M., and N. T. Dunford. 2019. Fractionating of canola lecithin from acid degumming and its effect. Food Chem. 300:125217. https://doi.org/10.1016/j.foodchem.2019.125217.

\section{ORCIDS}

Ali Ubeyitogullari @ https://orcid.org/0000-0003-1636-9681

Syed S. H. Rizvi ๑ https://orcid.org/0000-0001-9518-1243 